\title{
Enzyme-Mediated Ring-Opening Polymerization of Pentadecalactone to Obtain Biodegradable Polymer for Fabrication of Scaffolds for Bone Tissue Engineering
}

\author{
V. A. Korzhikov, ${ }^{1,2}$ K. V. Gusevskaya, ${ }^{1}$ E. N. Litvinchuk, ${ }^{1}$ \\ E. G. Vlakh,, ${ }^{1,2}$ and T. B. Tennikova ${ }^{1,2}$ \\ ${ }^{1}$ Institute of Macromolecular Compounds RAS Bolshoy Prospect 31, Saint Petersburg 199004, Russia \\ ${ }^{2}$ Chemistry Department, Saint-Petersburg State University Peterhof, Universitetskii Prospect 26, Saint Petersburg 198504, Russia
}

Correspondence should be addressed to V. A. Korzhikov; v_korzhikov@mail.ru

Received 16 April 2013; Accepted 20 August 2013

Academic Editor: Marek Cypryk

Copyright (c) 2013 V. A. Korzhikov et al. This is an open access article distributed under the Creative Commons Attribution License, which permits unrestricted use, distribution, and reproduction in any medium, provided the original work is properly cited.

The optimization of enzyme-mediated polymerization of pentadecalactone (PDL) was performed to obtain macromolecular products suitable for generation of 3D cell supports (scaffolds) for bone tissue engineering. Such parameters as temperature, monomer/enzyme ratio, and monomer concentration were studied. The maximum molecular weight of synthesized polymers was about 90,000. Methods allowing the introduction of reactive double bonds into polypentadecalactone (polyPDL) structure were developed. The macroporous matrices were obtained by modification of thermoinduced phase separation method.

\section{Introduction}

The development of synthesis and application of biodegradable polymers represent great achievement due to ecological [1] and medical problems [2] associated with utilization of carbon-chained nondegradable polymers. One of the most emerging classes of synthetic biodegradable polymers is aliphatic poly(hydroxy acids) (PHAs) [3]. Their physical properties are close to most plastics [4], but possessing of ester bonds in the main chain allows polymer degradation via chemical or enzymatic hydrolysis [5]. It is known that the time of degradation can be controlled by varying the monomer units in a polymer chain [6].

In spite of the fact that PHAs can be obtained via polycondensation process, the polymers with fine and controllable properties are usually derived using ring-opening polymerization (ROP) of lactides or lactones of corresponding HAs [7]. Generally, such type of polymerization is initiated and catalyzed by organometallic substances, like stannous octoate $\left(\mathrm{Sn}[\mathrm{Oct}]_{2}\right)[8,9]$, zinc lactate $\left(\mathrm{Zn}[\mathrm{Lac}]_{2}\right)[10]$, and many others $[7,9,11,12]$. These initiators allow obtaining the polymers with various molecular weights (MWs) and quite narrow molecular weight distribution (MWD). The main drawback of the mentioned method is that the resulting polymers contain metal ions that further become part of the polymer materials [1].

Relatively recently the novel approach to synthesize PHAs via $\mathrm{ROP}$, namely, enzyme-mediated ring-opening polymerization (EMROP), was developed and thoroughly studied by numerous scientific groups [1,13-22]. Usually, such polymerization is performed in the presence of various lipases [1822], for example, the enzymes catalyzing the ester bond cleavage via its hydrolysis. However, in nonpolar organic media and in the absence of water, the same enzymes enable the opening of the lactone cycle followed by new ester bond formation $[13,14]$. Very detailed and numerous data on EMROP produced at different conditions can be found in literature [23-26]. However, the polymers with low or mediate MW, mostly reported in cited papers, cannot be used for material construction. In our study, we optimized EMROP conditions in order to synthesize the macromolecular products with high MW allowing the formation of biodegradable supraporous scaffolds for bone tissue engineering using thermally induced phase separation (TIPS) method [27]. 
The presented paper demonstrates the results on the development of optimized experimental strategy to obtain the biodegradable polymers suitable for supraporous scaffold construction using enzyme-mediated synthesis in non-polar medium. The development of easy laboratory-scale technique to synthesize polypentadecalactone (polyPDL) of high MW needed for material construction represents a supplementary objective of presented research.

\section{Experimental}

2.1. Materials and Instruments. The monomer $\omega$-pentadecalactone (PDL, 98\%) was purchased from Aldrich and used without additional purification. Before polymerization, the reagent was characterized by proton nuclear magnetic resonance (1H NMR): $4.15(2 \mathrm{H}, \mathrm{t}), 2.35(2 \mathrm{H}, \mathrm{t}), 1.64(4 \mathrm{H}, \mathrm{m})$, and $0.85(22 \mathrm{H}$, br s) ppm. The enzymes Candida rugosa lipase (CRL) and acrylic resin immobilized Candida antarctica lipase $B$ (CALB, Novozyme-435) possessing specific activity $\geq 40000 \mathrm{U} / g$ and $\geq 10000 \mathrm{U} / g$, respectively, 2-hydroxyethyl methacrylate (HEMA), and stannous octoate were purchased from Sigma-Aldrich. Toluene, chloroform, and methanol were the products of ZAO "Vecton." Toluene was dried over calcium hydride and distilled. HPLC grade THF was purchased from Merck.

Syntheses of polymers, as well as drying of enzymes and products, were carried out in Schlenck tubes (Aldrich) connected to a vacuum-argon line provided with oil vacuum pump 2B-1.1 (Gidromekh). To seal the reaction tubes and bottles with solvents, Precision Seal rubber septa caps (Aldrich) were used.

The precise heating of reaction mixture was reached by the application of magnetic stirrer MR Hei-Standard (Heidolph) equipped with temperature controller, as well as using a glycerol bath, while the stirring of polymerization medium was provided using an IKA T-16 basic overhead stirrer.

For concentration of polymer solutions, IR-1 rotary evaporator (Khimlaborpribor) was used. The intrinsic viscosity measurements were performed in Ostwald type viscometer (capillary diameter $0.37 \mathrm{~mm}, \mathrm{ZAO}$ "Neva-Reactiv") supplied by LOIP LT-912 cryothermostat (ZAO "LOIP") that was also applied for cryotropic phase separation at macroporous materials preparation.

The molecular weight (MW) and molecular weight distribution (MWD) analysis was produced using Shimadzu liquid chromatography consisting of LC-10AD pump and RID-10A refractometric detector and supplied with Waters Styragel HMW 6E analytical column. To calculate MW and MWD, LC Solution 1.24SP1 GPC software was used. Polystyrene standards synthesized and characterized at the Institute of Macromolecular Compounds of RAS by Dr. Ludmila Vinogradova were used to build a calibration curve.

The ${ }^{1} \mathrm{H}$ NMR spectra were recorded with Bruker AVANCE-400 instrument.

\subsection{Methods}

2.2.1. Enzyme-Mediated Polymerization of PDL. The typical procedure to obtain polyPDL was followed. $0.93 \mathrm{~mL}$ of

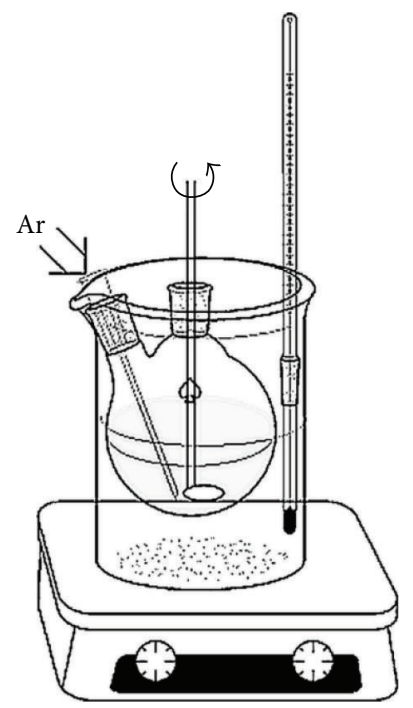

FIGURE 1: Scheme of reaction installation for EMROP of PDL.

toluene was dropped under intensive stirring and dry argon flow to the mixture of $400 \mathrm{mg}$ of monomer and $40 \mathrm{mg}$ of enzyme (CRL or CALB, $[\mathrm{M}] /[\mathrm{E}]=10 / 1 \mathrm{wt}$./wt.; other ratios were also tested, see Figure 5) in the reaction tube (Figure 1). The temperature was raised up to predetermined value (from 35 to $115^{\circ} \mathrm{C}$, see Table 4), and reaction was carried out until a solidification of reaction mixture (usually $1-3$ hours). If that did not occur, the reaction time was prolonged for 6 hours maximum. To stop the polymerization, the reaction tube was quenched into ice-cold water. The content of reaction tube was dissolved in the excess of hot chloroform. Then, polymer solution was separated from granules of solid-phase enzyme by filtration (Schott glass filter number 3 ). The filtrate was concentrated in a rotary evaporator, and the polymer was drop-wise precipitated to cold methanol. The precipitate obtained was isolated by filtration on glass Schott filter number 1 and dried in vacuum.

2.2.2. Enzyme-Mediated Polymerization of PDL in a Presence of 2-Hydroxymethacrylate (HEMA). The synthetic procedure to obtain polyPDL-HEMA was the same as that applied for synthesis of polyPDL. The only difference was the addition of HEMA to the reaction mixture ([M]/[HEMA] $=20$ and $40 \mathrm{~mol}$ ratio). The derived polymer was dried by sublimation, sealed and stored in a freezer at $-20^{\circ} \mathrm{C}$.

2.2.3. Radical Reaction of PolyPDL-HEMA. A sample of $150 \mathrm{mg}$ of polyPDL-HEMA and $7.5 \mathrm{mg}$ of radical initiator $2,2^{\prime}$-azo-bis-isobutyronitrile (AIBN) ([polyPDL-HEMA]/ [AIBN] $=20 / 1 \mathrm{wt}$./wt.) was inserted into the ampule and dissolved in $1 \mathrm{~mL}$ of dry toluene ([polyPDL-HEMA]/[toluene] = $1 / 7 \mathrm{wt} / \mathrm{wt})$. The ampule was sealed and placed into preheated up to $70^{\circ} \mathrm{C}$ thermostat and kept there for 24 hours. Then, the ampule was cooled, down and the polymer was precipitated in cold methanol, filtered, and dried over calcium chloride. 


\subsubsection{Polymer Analysis}

(1) ${ }^{1}$ H NMR Spectroscopy. The structures of synthesized polymers were confirmed by ${ }^{1} \mathrm{H}$ NMR spectra recorded in ${ }^{6} \mathrm{~d}$ chloroform $\left(\mathrm{CDCI}_{3}\right)$.

(2) Intrinsic Viscosity Measurement. To get the intrinsic viscosity $([\eta])$ of synthesized polymers dissolved in chloroform, Ostwald capillary viscometer was used. The flow time measurements were performed at $25^{\circ} \mathrm{C}$ for the following polymer concentrations: $1.50,1.33,1.19,1.05$, and $0.94 \pm 0.01 \mathrm{~g} / \mathrm{dL}$; then, $\eta_{\mathrm{sp}} / c$ parameter was calculated and extrapolated to the zero concentration to establish $[\eta]$. No Mark-Houwink equation was found for polyPDL in the literature.

(3) Gel Permeation Chromatography (GPC). To evaluate MW of synthesized samples, their solutions in THF with concentrations of $0.15 \mathrm{wt} . \%$ and $0.25 \mathrm{wt}$.\% were injected into Styragel column via $50 \mu \mathrm{L}$ valve loop and eluted at $0.3 \mathrm{~mL} / \mathrm{min}$ using THF as a mobile phase. The elution curves obtained were converted into MWD ones using a preliminary built calibration curve (polystyrene standards).

\subsubsection{Macroporous Matrices Fabrication}

Formation of Macroporous Matrices via Thermally Induced Phase Separation (TIPS) Technique. In a glass tube, $1 \mathrm{wt} . \%$ solution of a mixture of polyPDL and polyPDL-HEMA (from 85 to 15 wt.\%, resp.) in 1,4-dioxane containing 1.5 wt.\% of water and $1 \mathrm{wt} . \%$ of AIBN was prepared. To realize simultaneous homogenization of a prepared solution and free-radical initiation, the mixture was heated up to $65^{\circ} \mathrm{C}$ and sustained during 2 hours. After that the reaction medium was slowly cooled down up to occurrence of solid-liquid phase separation and quenched in liquid nitrogen. Then, the tube was placed into a fuming liquid nitrogen bath at $-40^{\circ} \mathrm{C}$, and $10-$ $15 \mathrm{~mL}$ of ethanol was added in order to extract frozen dioxane from the formed pores. The bath together with the tube was shook for 3 hours, and every $30 \mathrm{~min}$, ethanol was exchanged on a fresh portion. Then, the matrix was left in the excess of ethanol in a freezer $\left(-20^{\circ} \mathrm{C}\right)$ for 2 days and further dried at room temperature.

\section{Results and Discussion}

As it was noticed, the final goal of the presented research was to obtain biodegradable polypentadecalactone (polyPDL) with molecular weight sufficient for supraporous material preparation. Enzyme-mediated synthesis, which allows formation of polymers with controlled molecular characteristics, was chosen to reach the goal. Nevertheless, the first experiments were directed on a comparison of chemical and enzymatic methods to synthesize the same macromolecular product.

3.1. Comparison of Enzyme-Mediated and Chemically Catalyzed Ring-Opening Polymerization: Preliminary EMROP Optimization. According to our experiments, the ringopening polymerization of lactones can be performed at
TABLE 1: Reaction yield and polymer intrinsic viscosity at stannous octoate initiated ROP of PDL.

\begin{tabular}{lccc}
\hline Sample number & $T,{ }^{\circ} \mathrm{C}$ & Yield, $\%$ & {$[\eta], \mathrm{dL} / \mathrm{g}$} \\
\hline 1 & 120 & 5 & Not determined \\
2 & 160 & 9 & Not determined \\
3 & 200 & 64 & 0.38 \\
4 & 220 & 61 & 0.33 \\
\hline
\end{tabular}

Conditions: bulk process; reaction time-70 hours; $[\mathrm{PDL}] /\left[\mathrm{Sn}(\mathrm{Oct})_{2}\right]$ molar ratio- $50: 1$.

high temperature either in a sealed ampoule or in an evacuated Schlenk tube. Also the process can be carried out at a relatively lower temperature using double-neck flask under argon atmosphere. While the first two methods give similar and good results (meaning the reaction yield and MW of a product), the latter demonstrates definite advantage because it is much less volatile.

In the present experiments, the chemically catalyzed ROP of PDL was initiated by stannous octoate and performed in a bulk in vacuum-sealed ampoule.

From the data presented in Table 1, one can see that synthesis of a real macromolecular product requires application of quite high temperatures. In comparison, the application of similar conditions to another monomer, namely, L-lactide, resulted in a product with $[\eta]=0.7 \mathrm{dL} / \mathrm{g}$ at $150^{\circ} \mathrm{C}$. Thus, it is obvious that reactivity of PDL in polymerization initiated by stannous octoate seems to be relatively low, this is in accordance with previously published data $[9,14]$.

The attempts to realize bulk EMROP of PDL in ampoule using two commercial enzymes Candida rugosa lipase (CRL) and Candida antarctica lipase B (CALB, Novozyme 435) led to formation of oligomers with very low molecular weight. In most cases, the product appeared as a fine dispersed dust in non-solvating (cold methanol) media. Additionally, the yield of polymerization never exceeded 2-3\%. The reason for such effect can be explained by a difference of mechanisms of enzyme-mediated and chemically catalyzed reactions $[8,13]$. When the polymerization process is initiated by stannous octoate, the lactone cycle is cleaved to form active specie, and then, the propagation occurs via nucleophilic attack of neighboring monomer molecules. On the contrary, in the case of EMROP, the repeating cycles of enzymatic catalysis followed by formation and dissociation of enzyme-monomer complex are necessary for polymerization to proceed. Hence, the synthesis of the discussed polymer via chemically initiated ROP looks favorable being performed by reaction in a bulk of monomers with well-dispersed initiators, while for enzymemediated ROP of the same monomer, the sufficient diffusional mobility of enzyme in reaction mixture is required. The realization of such kind of polymerization in toluene solution at intensive mixing should improve the diffusion of substrate molecules to enzyme active sites and product withdrawing, as well as minimizing a probability of side reactions. The use of toluene as a solvent was dictated by good solubility of PDL, high boiling point, and high hydrophobicity. Finally, the reaction was performed in a double-necked flask under argon atmosphere and at intensive mixing of reaction medium (Figure 1). 
TABLE 2: EMROP of pentadecalactone. Dependence of reaction yield and polymer intrinsic viscosity on amount of water added to the enzyme before the reaction.

\begin{tabular}{lccc}
\hline Sample number & $\mathrm{H}_{2} \mathrm{O}$, wt.\% & Yield, \% & {$[\eta], \mathrm{dL} / \mathrm{g}$} \\
\hline 5 & 1.5 & 1 & - \\
6 & 2.5 & - & - \\
7 & 0 & 88 & 0.28 \\
\hline
\end{tabular}

Conditions: CALB; $75^{\circ} \mathrm{C} ;[\mathrm{M}] /[\mathrm{E}]=10 / 1 \mathrm{wt} . / \mathrm{wt}$; $[\mathrm{M}]$ concentration-50 wt.\%; reaction time -6 hours.

TABLE 3: EMROP of pentadecalactone. Dependence of product yield and polymer intrinsic viscosity on reaction time.

\begin{tabular}{lccc}
\hline Sample number & Time, $\mathrm{h}$ & Yield, $\%$ & {$[\eta], \mathrm{dL} / \mathrm{g}$} \\
\hline 9 & 28 & 93 & 0.21 \\
8 & 4 & 92 & 0.38 \\
\hline Conditions: & $\mathrm{CALB} ; 65^{\circ} \mathrm{C} ;[\mathrm{M}] /[\mathrm{E}]$ & $=10 / 1$ wt./wt.; $[\mathrm{M}]$ & concentration-
\end{tabular}
50 wt.\%.

The application of the suggested experimental installation resulted in high reaction yields and intrinsic viscosity values of polymers obtained using CALB, while for the CRL case, the yield never exceeded $10 \%$. Therefore, all further experiments were carried out using first commercial lipase. The advantage of CALB can be also explained by its immobilization on acrylic resin that leads to additional stability of enzyme macromolecule. Moreover, some definite contents of water within relatively hydrophilic resin can be a key factor for successful catalysis because it is known that enzyme activity in nonpolar organic media still depends on water presence [2831]. The small amount of water is necessary to preserve the active conformation of enzyme molecule and plays the role of the additional initiator of the polymerization process $[7,31]$. According to that, the hydrophobicity and hygroscopicity of the chosen organic solvent is of a great importance. Thus, the solvent has to be hydrophobic enough and non-hydroscopic to avoid removal of water from surrounding enzyme. From this point of view, it was interesting to evaluate the impact of small amounts of water on the activation of polymerization process. For this purpose, the commercial CALB (immobilized form) was dried over $\mathrm{P}_{2} \mathrm{O}_{5}$, and then, different portions of water were added just before synthesis. The results of these experiments are presented in Table 2.

It is obvious that even very small amounts of water added to the enzyme before mixing with monomer solution completely stopped the polymerization, while the application of enzyme in its initial form led to polymer formation. It means that the content of water provided by swollen resin is enough for the catalyzing process.

The very curious effect concerning the reaction time was observed. Thus, the reaction mixture was solidified after several hours (Table 3, sample 8), whereas the continuation of a process till 24 hours led to its total clarification followed by a fall of intrinsic viscosity (Table 3, sample 9). This phenomenon might be explained by postpolymerization chain cleavage (inverse enzymatic process), as well as by interchain
TABLE 4: EMROP of pentadecalactone. Dependence of reaction time, yield, and intrinsic viscosity of resulting products on reaction temperature.

\begin{tabular}{|c|c|c|c|c|c|c|}
\hline $\begin{array}{l}\text { Sample } \\
\text { number }\end{array}$ & $T,{ }^{\circ} \mathrm{C}$ & Time, h & Yield, \% & {$[\eta], \mathrm{dL} / \mathrm{g}$} & $\begin{array}{c}M_{w} \times 10^{-3} \\
(\mathrm{GPC})^{*}\end{array}$ & $M_{w} / M_{n}^{*}$ \\
\hline 10 & 35 & 6.0 & 3 & - & - & - \\
\hline 11 & 45 & 2.0 & 87 & 0.30 & - & - \\
\hline 12 & 55 & 1.0 & 87 & 0.54 & 39.3 & 1.78 \\
\hline 13 & 65 & 1.5 & 85 & 0.56 & 29.1 & 1.58 \\
\hline 14 & 75 & 3.0 & 89 & 0.59 & - & - \\
\hline 15 & 85 & 3.0 & 90 & 0.75 & - & - \\
\hline 16 & 95 & 5.0 & 86 & 0.79 & - & - \\
\hline 17 & 105 & 2.5 & 91 & 1.02 & 88.0 & 1.65 \\
\hline 18 & 115 & 2.0 & 84 & 0.89 & - & - \\
\hline
\end{tabular}

TABLE 5: Dependences of polyPDL yield, reaction time (visual fixation of polymerization mixture solidification), and product intrinsic viscosity on monomer concentration.

\begin{tabular}{lcccc}
\hline Sample number & Time, $\mathrm{h}$ & {$[\mathrm{M}]$ conc., wt.\% } & Yield, $\%$ & {$[\eta], \mathrm{dL} / \mathrm{g}$} \\
\hline 19 & 1.5 & 50 & 85 & 0.56 \\
20 & 6 & 25 & 90 & 0.73 \\
21 & 6 & 17 & 84 & 0.56 \\
\hline
\end{tabular}

Reaction conditions: $T=65^{\circ} \mathrm{C},[\mathrm{M}] /[\mathrm{E}]=10 / 1 \mathrm{wt} . / \mathrm{wt}$.

side reactions leading to an increasing number of short fragments.

According to this result, the time of a process, when the reaction mixture became solid, has been chosen for further experiments. The maximal MW of the polymer obtained that was reached at chosen conditions was also taken into consideration.

From preliminary investigations, it was also found that the temperature of enzymatic reaction is equal to $65^{\circ} \mathrm{C}$ and $[\mathrm{M}] /[\mathrm{E}]$ ratio is equal to $10 \mathrm{wt} . / \mathrm{wt}$. and monomer concentration of $50 \mathrm{wt} . \%$ led to a maximum yield and final product intrinsic viscosity. Therefore, these conditions were taken as a reference for further experiments.

\subsection{Optimization of PDL EMROP Conditions}

3.2.1. Effect of Reaction Temperature on Yield and Intrinsic Viscosity of Synthesized PolyPDL. To evaluate the effect of reaction temperature on the mentioned parameters, a series of syntheses at identical conditions with only temperature variation was performed. The results obtained are presented in Table 4 .

According to results presented in Table 4, at temperatures below $40^{\circ} \mathrm{C}$, the polymerization proceeds only to a negligible extent with very low yield of a product. Increasing the temperature above $45^{\circ} \mathrm{C}$ leads to formation of polymers with quite high yields. These values (86-91\%) remain constant in a whole studied temperature interval. At the same time, the growth of intrinsic viscosity takes place when the temperature 
TABLE 6: Effects of polymer yield, reaction time, and product intrinsic viscosity on [M]/[HEMA].

\begin{tabular}{lcccccc}
\hline Sample number & Time, $\mathrm{h}$ & {$[\mathrm{M}] /[\mathrm{HEMA}], \mathrm{mol} / \mathrm{mol}$} & Yield, $\%$ & {$[\eta], \mathrm{dL} / \mathrm{g}$} & $M_{w} \times 10^{-3}(\mathrm{GPC})$ & $M_{w} / M_{n}^{*}$ \\
\hline 22 & 5 & Control & 87 & 0.58 & 26.7 & 1.43 \\
23 & 5 & 20 & 85 & 0.21 & 16.4 & 1.56 \\
24 & 5 & 40 & 88 & 0.32 & 22.0 \\
\hline
\end{tabular}

Reaction conditions: $T=55^{\circ} \mathrm{C},[\mathrm{M}] /[\mathrm{E}]-30 \mathrm{wt} . / \mathrm{wt} .,[\mathrm{M}]-25 \mathrm{wt} . \%$.

${ }^{*}$ The ratio is given for macromolecular peak only, while for the whole sample, the PDI is much higher.

is increased from $45^{\circ} \mathrm{C}$ to $105^{\circ} \mathrm{C}$. Further temperature increasing does not lead to $[\eta]$ growth. This result can be caused by partial loss of enzyme activity because of the removal of some amount of bound water. Also, the high temperature can be a reason of conformational changes in protein macromolecule.

Figure 3 demonstrates the complex graphs related to the dependences of reaction time and intrinsic viscosity on applied temperature. Obviously, two local intervals with optimal temperature can be registered.

First optimum is within the temperature range $55-75^{\circ} \mathrm{C}$. At this temperature range, the product with quite high viscosity is obtained at a minimum reaction time. The presence of such optimal zones means that the product with high viscosity (high MW) can be obtained at quite short reaction times. The second optimum is detected in a narrow range of temperatures, for example, between $100^{\circ} \mathrm{C}$ and $110^{\circ} \mathrm{C}$. Here, the polymers with maximum viscosity are formed.

The first optimum represents the special interest because it allows synthesis of really macromolecular products at very low temperatures. The polymerization at similar temperature values is also possible at chemical initiation by alkali-earth metals and lanthanide alkoxides [7, 32, 33]. Though, such methods necessarily require application of special experimental techniques, namely, inert atmosphere (glove-box) and high vacuum (vacuum line), because the air moisture easily hydrolyzes the counted initiators. Contrary to that, EMROP catalyzed by CALB can be easily performed at mild heating, intensive mixing, and under argon flow in order to exclude the effect of air moisture on enzyme activation. Thus, EMROP demonstrates significant experimental advantages, especially regarding laboratory scaled-up synthesis. Moreover, the mild reaction conditions should allow introduction of reactive terminal groups, such as double bonds, which is not possible at high temperature polymerization.

As to the second optimum, it is interesting that the enzyme keeps its activity at the temperatures above $100^{\circ} \mathrm{C}$, which is much higher than physiological conditions. In fact, the reaction proceeds at nearly boiling point of toluene. This phenomenon can be related to the fact that the polymerization is performed in hydrophobic organic solvent (dry toluene). From classic enzymology, it is known that thermoinactivation of biocatalyst requires the participation of water, which promotes conformational mobility and activates a decomposition of protein molecule. Dry toluene contains no water, and, thus, the enzyme molecules seem to be stabilized by organic solvent. This effect can be a reason for remaining enzyme activity and makes EMROP the prefered method to obtain the polymer of high MW in a large scale. Additionally, this method allows synthesis of macromolecular products free of metal admixtures, and enzyme could be easily separated by filtration of polymer solution in chloroform.

3.2.2. Effects of Reaction Time, Product Yield, and Intrinsic Viscosity on Monomer/Enzyme Ratio. The effect of monomer to enzyme ratio on reaction time, poly(PDL) yield, and intrinsic viscosity was evaluated (Figure 4 ).

The presented data show that at monomer/enzyme ratio equals 2, the reaction is fast but results in the polymer with comparatively low MW and low yield. The increase of relative enzyme concentration leads to the formation of bigger amounts of activated monomer species, which initiate the elevated number propagating chains. This, in turn, leads to predominating synthesis of short polymer chains. The latter is in a good agreement with low viscosity of the resulting product. Moreover, relatively high enzyme content of biocatalyst can probably promote the higher extent of side reactions (both inter- and intramolecular).

Ten times increase of PDL excess over enzyme molar concentration leads to the extension of reaction time. At the same time, the yield and intrinsic viscosity of poly(PDL) are growing. The graphs presented on Figure 4 clearly show that maximum reaction time causes the formation of polymer product with highest values of yield and viscosity $([\mathrm{M}] /[\mathrm{E}]$ $=30)$.

Further increasing the monomer to enzyme ratio did not lead to the yield and viscosity growth. This result can be diminished by low enzyme concentration number of monomers (PDL) participating in the polymerization process.

3.2.3. Effects of Reaction Time, Product Yield, and Intrinsic Viscosity on Monomer Concentration. The results obtained in the study of dependence of PDL EMROP parameters on monomer concentration are demonstrated in Table 5. Despite a good solubility of PDL in toluene, the application of highconcentrated solutions seems to be irrational because of their high viscosity. The conclusion from Table 5 is that decreasing the monomer concentration from 50 to $25 \mathrm{wt} \%$ prolongs the reaction time, as well as the product yield and intrinsic viscosity. Similar to $[\mathrm{M}] /[\mathrm{E}]$ effect, the result obtained can be explained by the diminishing number of activation acts and, thus, by the increasing of both kinetic and material lengths of polymer chains.

It is important to note that in the cases of samples 20 and 21 , no solidification of reaction mixture was observed, and the reaction was stopped after 6 hours according to the above specified protocol (see Section 3.2.1.). Obviously, increasing 


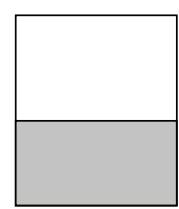

Solvent
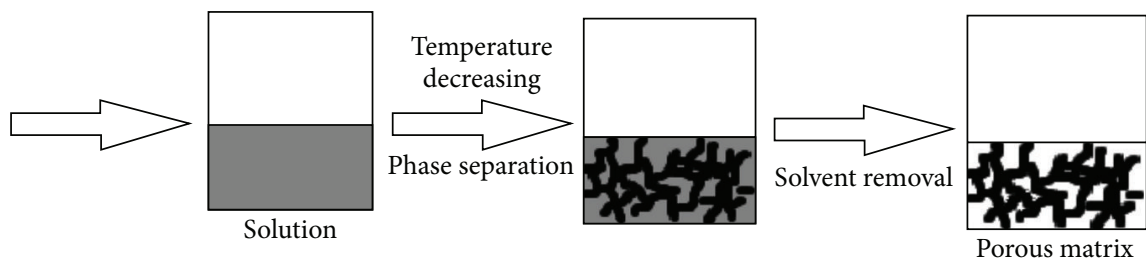

FIGURE 2: General scheme of matrix formation using TIPS technique.

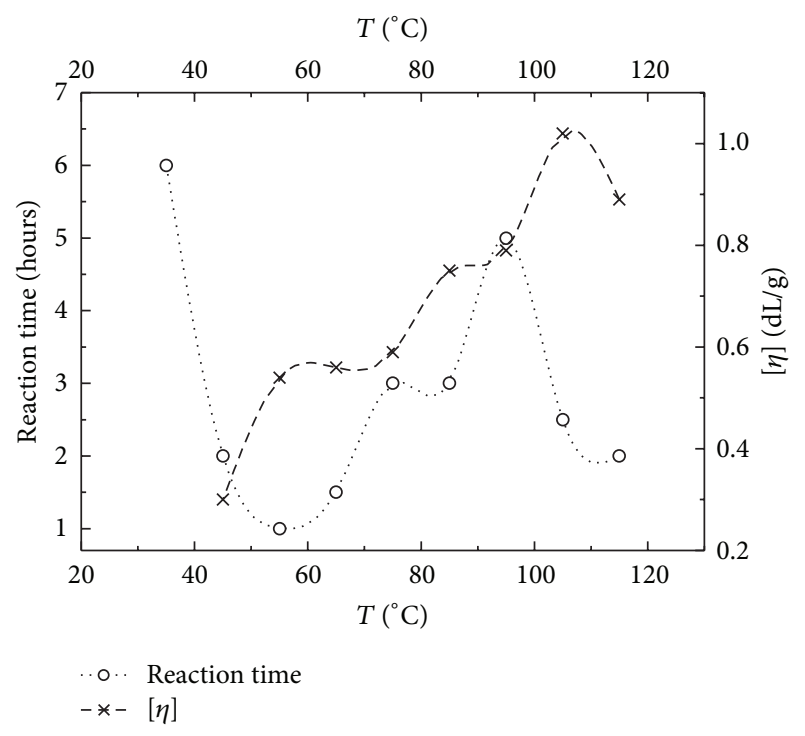

FIGURE 3: Temperature dependences of reaction time (visual detection of reaction mixture solidification) and polymer intrinsic viscosity. Reaction conditions: $[\mathrm{M}] /[\mathrm{E}]=10 / 1 \mathrm{wt} . / \mathrm{wt}$., $[\mathrm{PDL}]=50 \mathrm{wt} . \%$.

reaction time will lead to formation of products with higher viscosity values. The concentration of PDL equal to $25 \mathrm{wt} . \%$ seems to be optimal to obtain the polymer with sufficient molecular characteristics within a reasonable time interval.

Summarizing the results presented in this section, we can conclude that two optimal temperature intervals were found. These are $50-85^{\circ} \mathrm{C}$ (for temperature sensitive reactions) and $100-110^{\circ} \mathrm{C}$ (high-molecular product formation). The optimal monomer/enzyme ratio and optimal monomer concentration were established as $30 \mathrm{wt}$./wt. and $25 \mathrm{wt} . \%$, respectively.

3.3. Synthesis of Poly(PDL)-HEMA: EMROP Facilities for Molecular Architecture Variation. As it was pointed in the introduction, the final goal of this work was to develop and optimize the EMROP method to obtain the product, namely, poly(PDL), which could be appropriate for fabrication of rigid scaffolds for bone tissue engineering. According to our idea, this should be a polymer bearing active double bond

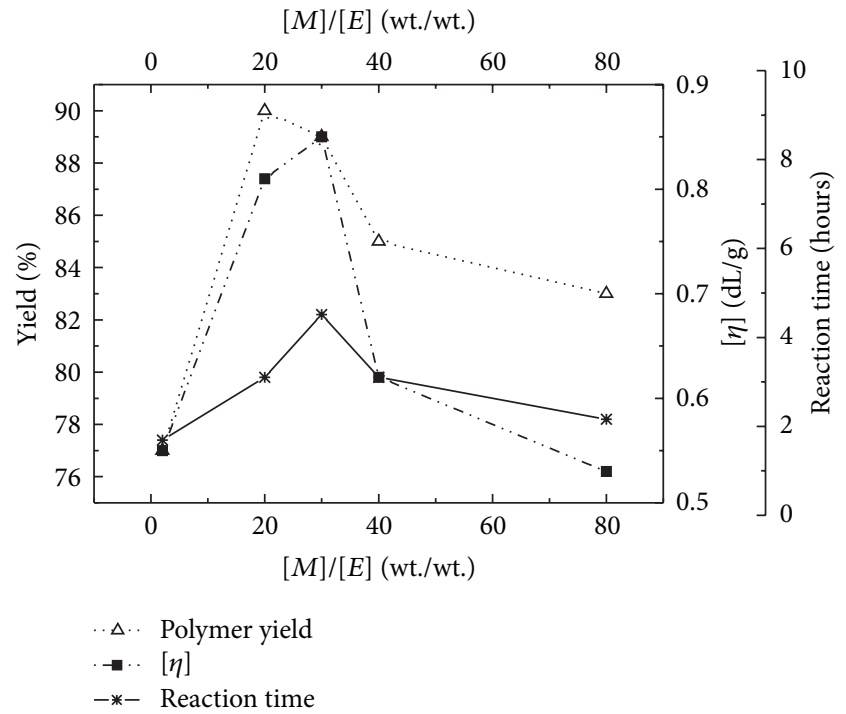

FIgURE 4: Graphs of dependences of polyPDL yield, reaction time (visual fixation of solidification of reaction medium) and product intrinsic viscosity on $[\mathrm{M}] /[\mathrm{E}]$ ratio. Reaction conditions: $T=65^{\circ} \mathrm{C}$, monomer concentration-50 wt.\%.

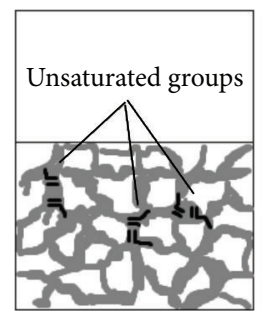

Cross-linking via free-radical reaction

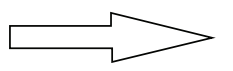

Chemical cross-links

FIGURE 5: Enhancement of mechanical properties of polymer matrix via chemical cross-linking.

in its molecular structure. These groups can be used both for regulation of mechanical properties of created support via radical cross-linking of polymer chains (Figure 5), and for grafting of hydrophilic reactive polymer intermediates for further biofunctionalization of scaffold surface. 


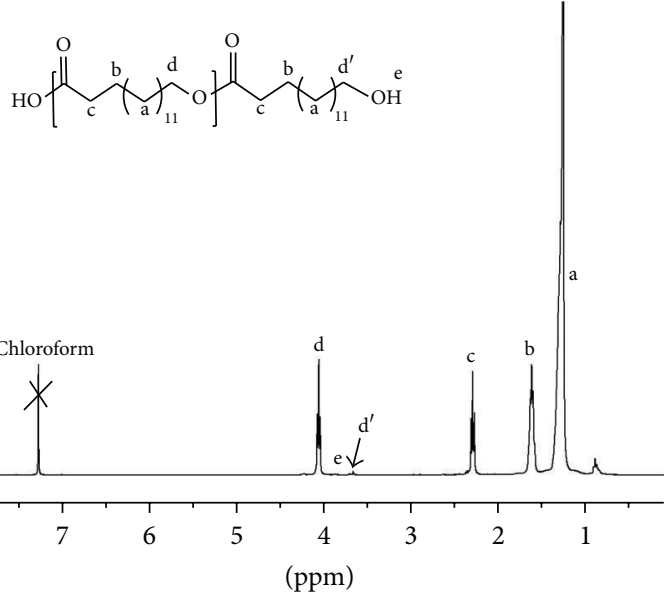

(a)

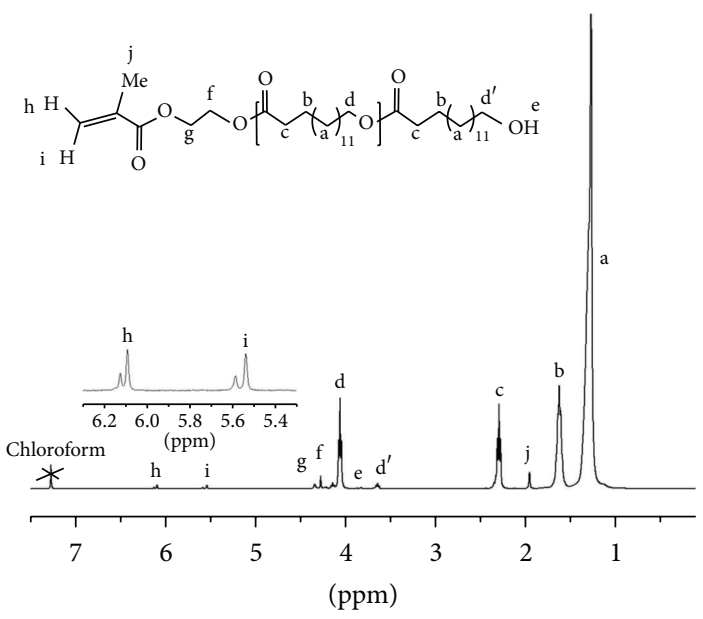

(b)

Figure 6: ${ }^{1} \mathrm{H}$ NMR spectra: (a)—polyPDL; (b) — polyPDL obtained in presence of HEMA.

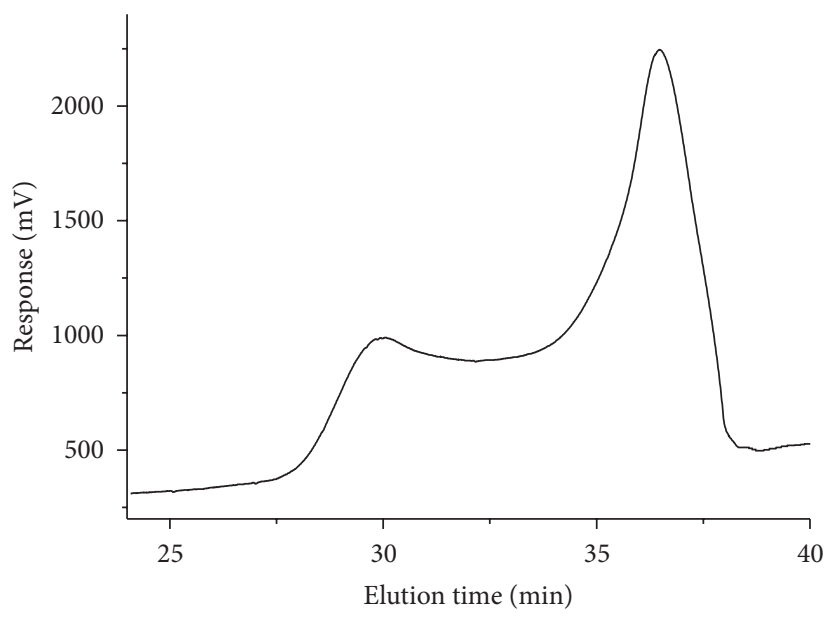

(a)

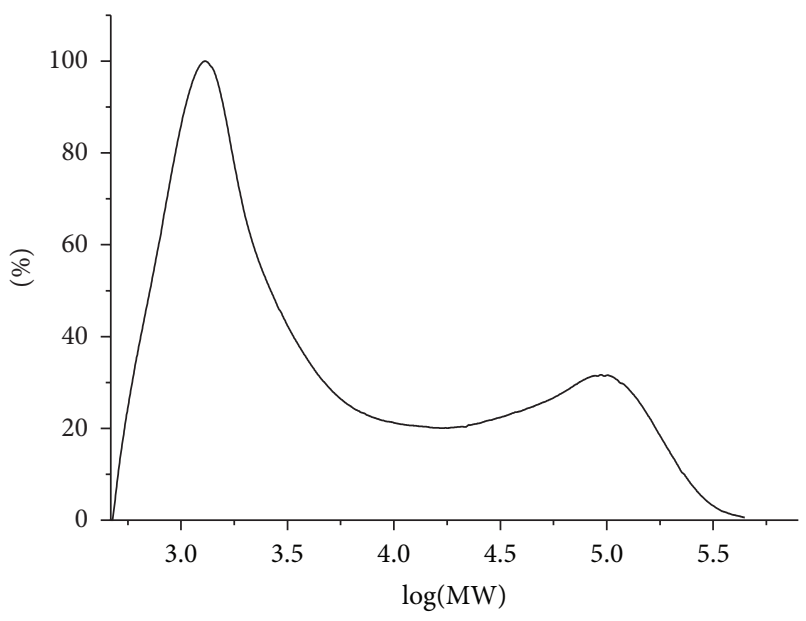

(b)

Figure 7: GPC elution (a) and MWD (b) curves for sample number 17 ([ $\eta]=1.02 \mathrm{dL} / \mathrm{g}$, see Table 4).

From mechanism of EMROP published elsewhere [14], it is known that participation of hydroxyl-containing compound is required for initiating a step. It is important that such a compound becomes the part of the resulting polymer structure. Initially, such initiation takes place because of water that is present in acrylic resin used for CALB immobilization. This process results in the appearance of carboxylic-end group on a polymer chain. The addition of some amounts of alcohol to the reaction mixture will provoke another type of initiation resulting in ester-end groups formation [7].

In our study, we developed the original approach; namely, 2-hydroxymethacrylate (HEMA) was used as both hydroxyland double-bond containing initiator. HEMA possesses a quite reactive methacrylate residue, which is separated from hydroxyl by two methylene groups.

Two polymerization runs were performed at mild temperature and different PDL/HEMA ratios. In parallel, the control synthesis at the same conditions but without HEMA addition was produced (Table 6). It was established that introduction of significant amounts of HEMA to the polymerization mixture led to decrease of the products' intrinsic viscosity, while the yield remained on the same level. This fact confirms HEMA participating in the initiation of PDL ROP and its entering into the polymer structure. The more HEMA is introduced into reaction mixture, the shorter polymer chains are obtained. This fact has to be taken into consideration, because too low MW of synthesized and modified polymer prevents the following porous matrix formation based on temperature-induced phase separation.

The presence of end chain methacrylate groups was also confirmed by ${ }^{1} \mathrm{H}$ NMR spectroscopy (Figure 6). In the NMR, spectra of polyPDL obtained in the presence of HEMA wellidentified signals of diastereotopic protons of methacrylate group at 6.09 and $5.54 \mathrm{ppm}$ are detected. A signal at $1.94 \mathrm{ppm}$, which confirms the presence of HEMA introduced with methyl group, was also found. 


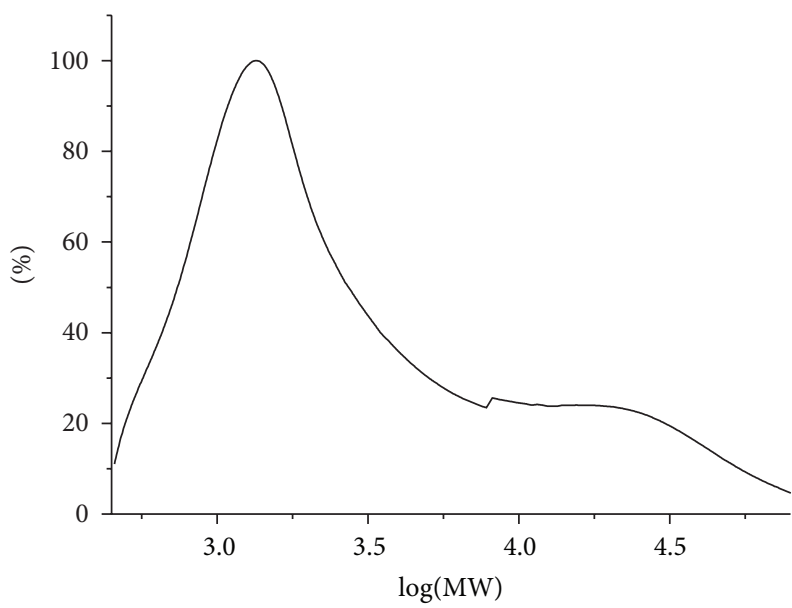

(a)

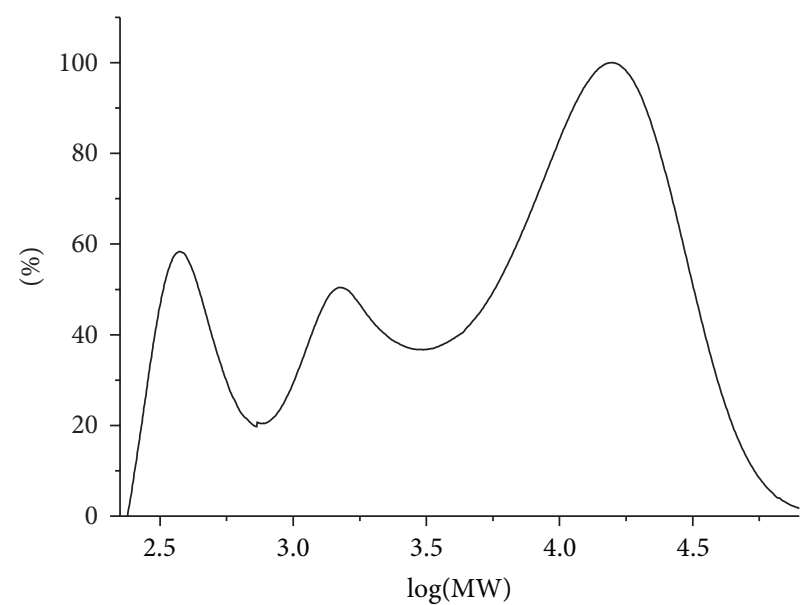

(b)

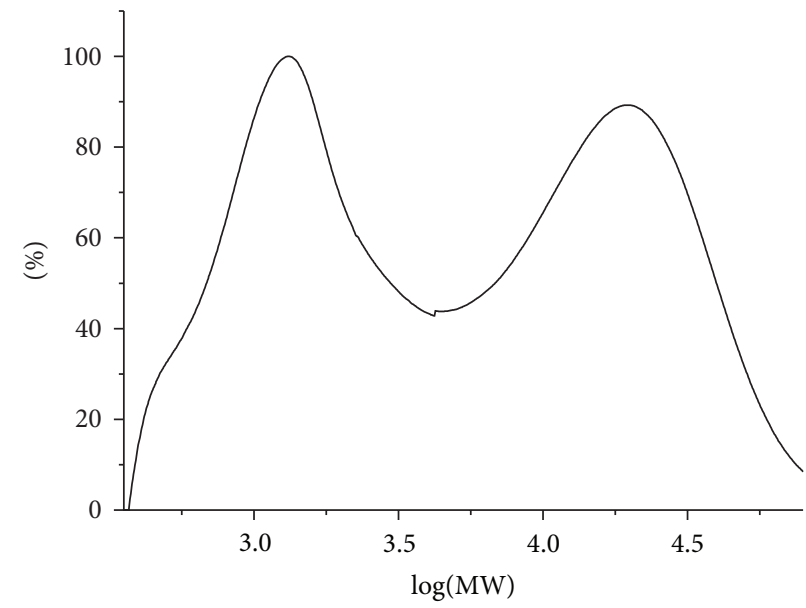

(c)

FIGURE 8: MWD curves calculated from GP chromatograms: (a)—sample 22 (control), (b) —sample 23 ([M]/[HEMA] = 20 mol. ratio), (c)— sample $24([\mathrm{M}] /[$ HEMA $]=40 \mathrm{~mol}$. ratio); for details, see Table 6 .

From the spectrum on Figure 6(b), the HEMA content was calculated as the integral ratio of signals corresponding to the protons of HEMA residue (Figure 6(b), j (1.94 ppm), $\mathrm{h}$ $(6.09 \mathrm{ppm})$, and i (5.54 ppm)) and those of methylene group adjacent to carbonyl group in monomer units (Figure 6(b), c $(2.28 \mathrm{ppm})$ ). It was found that there is $7 \mathrm{~mol}$.\% of HEMA in the synthesized polymer product. Moreover, the functionality of macromonomer was evaluated as the relation of number of HEMA groups (Figure 6(b), i (5.54 ppm)) to the number of the total molecules of poly(PDL), determined from terminal $-\mathrm{CH}_{2} \mathrm{CH}_{2} \mathrm{OH}$ groups content (Figure 6(b), d' (3.64 ppm)). The obtained functionality value is equal to $82 \%$. This means that more than a half of the poly(PDL) chains are initiated with HEMA and finally possess HEMA moiety in their structure.

Free-radical polymerization with participation of introduced methacrylic double bonds was performed using the sample 23 (Table 6). The reaction was carried out in toluene in the presence of AIBN as an initiator at $60^{\circ} \mathrm{C}$ for 19 hours. As a result, the intrinsic viscosity of poly (PDL) increased from 0.21 for initial polymer to $0.30 \mathrm{dL} / \mathrm{g}( \pm 0.4 \mathrm{dL} / \mathrm{g})$. This can be a reason for concluding that introduced HEMA moieties enable to regulate macromolecular chains length via their cross-linking which, in turn, influence the mechanical properties of formed polymer matrix.

3.4. GPC Studies of Poly(PDL) Obtained in Different Conditions. Additional to intrinsic viscosity measurements, GPC analysis of some samples of specific interest was performed to evaluate the molecular weights of synthesized polymer products. For that, the calibration curve plotted with application of polystyrene standards was used. The $M_{w}$ and $M_{w} / M_{n}$ values were presented in the foregoing tables.

Figure 7 represents the typical elution, and MWD curves are presented. The chromatogram usually consisted of two peaks that resulted in bimodal MW distribution.

The presence of two elution peaks found in our experiments is in good correlation with previously published data [34]. The authors of the cited paper discovered two types of molecular architectures obtained: linear and cyclic macromolecules. Obviously, these products will have different sizes and, thus, different retention characteristics in GPC. 


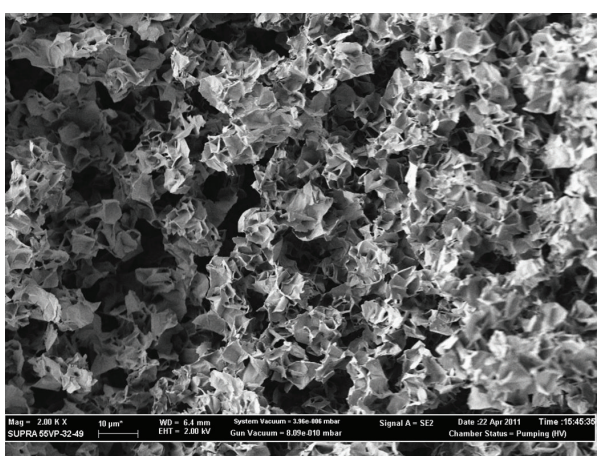

(a)

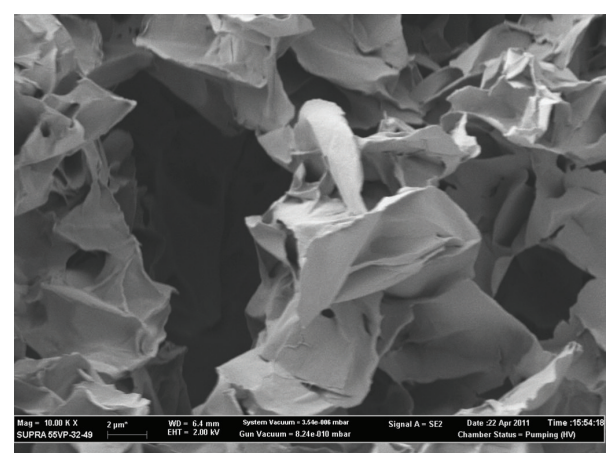

(b)

FiguRE 9: SEM microphotographs of PDL+PDL-HEMA-based macroporous materials: (a)—magnification $\times 2000$; (b) - magnification $\times 10000$.

Figure 8 demonstrates MWD curves related to the samples obtained without HEMA (Figure 8(a)) and in the presence of HEMA (Figures $8(\mathrm{~b})$ and $8(\mathrm{c})$ ). It is obvious that the introduction of HEMA into polymerization medium definitely affects the character of MWD. While the first curve is similar to that presented in Figure 7, the peaks ratio in the latter two cases significantly differs. The observed phenomenon can be explained by a tendency to decrease cyclic macromolecules formation along with increasing the amount of HEMA introduced into reaction mixture (Figures 8(a), 8(c), and $8(\mathrm{~b}))$. It means that the participation of HEMA in polymer structuring (end chain formation) dramatically decreases the probability of the appearance of cyclic macromolecular form.

\subsection{Formation of Poly(PDL)-Based Macroporous Supports via} Thermally-Induced Phase Separation (TIPS) and Freeze Solvent Extraction. The experiments approving the possibility of formation of macroporous materials based on poly(PDL) were carried out. For that, thermally-induced phase separation (TIPS) technique was applied (see Figure 2). On the first step, a homogenous mixture of poly(PDL) (sample 17, 85 wt.\%) with poly(PDL)-HEMA (sample 24,15 wt.\%) in 1,4dioxane containing $1.5 \mathrm{wt} . \%$ of water and $1 \mathrm{wt} . \%$ of AIBN was prepared and kept at $65^{\circ} \mathrm{C}$ for 2 hours. The slight opalescence was observed after one hour, which can be referred to the reaction-induced phase separation. Then slowly decreasing of temperature was performed until solid-liquid phase separation was observed. After a quenching of polymer matrix in liquid nitrogen, the freeze solvent extraction by ethanol was carried out within 3 days. This method is based on a good mixing of 1,4-dioxane with ethanol, low freezing point of the latter, as well as nonsolubility of poly(PDL) in alcohols. Thus, crystalline 1,4-dioxane was washed out from macroporous structure of the poly(PDL) by liquid ethanol at a temperature about $-40^{\circ} \mathrm{C}$. The SEM images of obtained materials are presented in Figure 9.

The microphotographs obtained demonstrate the uniform morphology of formed materials, which possess interconnected pore structure with mean pore size about $10 \mu \mathrm{m}$ (calculated from SEM images).

\section{Conclusions}

Both chemically catalyzed and enzyme-mediated methods were compared regarding the possibility of synthesis of poly(PDL) with high molecular weights. The advantage of the enzymatic method was demonstrated.

The optimized EMROP method was used to obtain poly(PDL)-HEMA macromolecules, which were shown to be perspective for formation of macroporous matrices with porous characteristics sufficient for tissue engineering scaffolds fabrication.

\section{Abbreviations \\ PHA: Poly(hydroxy acid) \\ EMROP: Enzyme-mediated ring-opening polymerization \\ TIPS: Thermoinduced phase separation \\ PDL: Pentadecalactone \\ MW: Molecular weight \\ CRL: Candida rugosa lipase \\ CALB: Candida antarctica lipase B \\ HEMA: 2-Hydroxyethylmethacrylate.}

\section{Acknowledgments}

The work was financially supported by the Russian Ministry of Education and Science (program "Scientific and scientificpedagogical personnel of innovative Russia," Agreements no. 8471 and no. 14.740.11.0382) and the Russian Foundation for Basic Research (Grant no. 11-03-00829-a).

\section{References}

[1] S. Kobayashi and A. Makino, "Enzymatic polymer synthesis: an opportunity for green polymer chemistry," Chemical Reviews, vol. 109, no. 11, pp. 5288-5353, 2009.

[2] J. Feijen, "Biodegradable polymers for medical purpose," in Polymeric Biomaterials, E. Piskin and A. S. Hoffman, Eds., pp. 62-77, Martinus Nijhoff Publishers, Dordrecht, The Netherlands, 1986. 
[3] A.-C. Albertsson and I. K. Varma, "Recent developments in ring opening polymerization of lactones for biomedical applications," Biomacromolecules, vol. 4, no. 6, pp. 1466-1486, 2003.

[4] T. H. Barrows, "Synthetic bioabsorbable polymers," in High Performance Biomaterials, M. Szycher, Ed., pp. 243-257, Technomic Publishing, Lancaster, Pa, USA, 1991.

[5] M. Vert, "Bioresorbable polymers for temporary therapeutic applications," Angewandte Makromolekulare Chemie, vol. 166, pp. $155-168,1989$.

[6] R. Y. Zhang and P. Ma, "Poly(alpha-hydroxyl acids) hydroxyapatite porous composites for bone tissue engineering. Preparation and morphology," Journal of Biomedical Materials Research, vol. 44, pp. 446-455, 1999.

[7] J.-P. Puaux, I. Banu, I. Nagy, and G. Bozga, "A study of Llactide ring-opening polymerization kinetics," Macromolecular Symposia, vol. 259, pp. 318-326, 2007.

[8] R. F. Storey and J. W. Sherman, "Kinetics and mechanism of the stannous octoate-catalyzed bulk polymerization of $\varepsilon$-caprolactone," Macromolecules, vol. 35, no. 5, pp. 1504-1512, 2002.

[9] H. von Schenck, M. Ryner, A.-C. Albertsson, and M. Svensson, "Ring-opening polymerization of lactones and lactides with $\mathrm{Sn}(\mathrm{IV})$ and Al(III) initiators," Macromolecules, vol. 35, no. 5, pp. 1556-1562, 2002.

[10] R. R. Gowda and D. Chakraborty, "Zinc acetate as a catalyst for the bulk ring opening polymerization of cyclic esters and lactide," Journal of Molecular Catalysis A, vol. 333, no. 1-2, pp. 167-172, 2010.

[11] X. Wang, K. Liao, D. Quan, and Q. Wu, "Bulk ring-opening polymerization of lactides initiated by ferric alkoxides," Macromolecules, vol. 38, no. 11, pp. 4611-4617, 2005.

[12] P. S. Umare, G. L. Tembe, K. V. Rao, U. S. Satpathy, and B. Trivedi, "Catalytic ring-opening polymerization of l-lactide by titanium biphenoxy-alkoxide initiators," Journal of Molecular Catalysis A, vol. 268, no. 1-2, pp. 235-243, 2007.

[13] D. Philippe, C. Olivier, and J. M. Raquez, Eds., Handbook of Ring-Opening Polymerization, WHILEY-VCH, Weinheim, Germany, 2009.

[14] S. Matsumura, "Enzymatic synthesis of polyesters via ringopening polymerization," Advances in Polymer Science, vol. 194, no. 1, pp. 95-132, 2006.

[15] A.-C. Albertsson and R. K. Srivastava, "Recent developments in enzyme-catalyzed ring-opening polymerization," Advanced Drug Delivery Reviews, vol. 60, no. 9, pp. 1077-1093, 2008.

[16] S. Matsumura, "Enzyme-catalyzed synthesis and chemical recycling of polyesters," Macromolecular Bioscience, vol. 2, pp. 105126, 2002.

[17] Y. Suzuki, S. Taguchi, T. Hisano, K. Toshima, S. Matsumura, and Y. Doi, "Correlation between structure of the lactones and substance specificity in enzyme-catalyzed polymerization for the synthesis of polyesters," Biomacromolecules, vol. 4, no. 3, pp. 537-543, 2003.

[18] S. Kobayashi, H. Uyama, S. Namekawa, and H. Hayakawa, "Enzymatic ring-opening polymerization and copolymerization of 8-octanolide by lipase catalyst," Macromolecules, vol. 31, no. 17, pp. 5655-5659, 1998.

[19] H. Uyama, K. Takeya, N. Hoshi, and S. Kobayashi, "Lipasecatalyzed ring-opening polymerization of 12-dodecanolide," Macromolecules, vol. 28, no. 21, pp. 7046-7050, 1995.

[20] S. Noda, N. Kamiya, M. Goto, and F. Nakashio, "Enzymatic polymerization catalyzed by surfactant-coated lipases in organic media," Biotechnology Letters, vol. 19, no. 4, pp. 307-309, 1997.
[21] K. Küllmer, H. Kikuchi, H. Uyama, and S. Kobayashi, "Lipasecatalyzed ring-opening polymerization of $\alpha$-methyl- $\delta$-valerolactone and $\alpha$-methyl-e-caprolactone," Macromolecular Rapid Communications, vol. 19, no. 2, pp. 127-130, 1998.

[22] C. Hedfors, E. Östmark, E. Malmström, K. Hult, and M. Martinelle, "Thiol end-functionalization of poly( $\epsilon$-caprolactone), catalyzed by candida antarctica lipase B," Macromolecules, vol. 38, no. 3, pp. 647-649, 2005.

[23] G. Broze, P. M. Léfèbvre, R. Jérôme, and Ph. Teyssiè, "Block copolymerization of 3,3-dimethyl-2-oxetanone. 1 . About the mechanism of $\alpha, \alpha$-disubstituted $\beta$-propiolactones block copolymerization," Macromolecules, vol. 12, pp. 1047-1051, 1979.

[24] P. Dubois, P. Degée, R. Jérôme, and Ph. Teyssié, "Macromolecular engineering of polylactones and polylactides. 8. Ringopening polymerization of $\varepsilon$-caprolactone initiated by primary amines and trialkylaluminum," Macromolecules, vol. 25, no. 10, pp. 2614-2618, 1992.

[25] H. Uyama and S. Kobayashi, "Enzyme-catalyzed polymerization to functional polymers," Journal of Molecular Catalysis B, vol. 19-20, pp. 117-127, 2002.

[26] H. Uyama, H. Kikuchi, and S. Kobayashi, "One-shot synthesis of polyester macromonomer by en-zymatic ring-opening polymerization of lactone in the presence of vinyl ester," Chemistry Letters, vol. 11, pp. 1047-1048, 1995.

[27] S. N. Yoon and G. P. Tae, "Porous biodegradable polymeric scaffolds prepared by thermally in-duced phase separation," Journal of Biomedical Materials Research, vol. 47, pp. 8-17, 1999.

[28] Y. Mei, A. Kumar, and R. A. Gross, "Probing water-temperature relationships for Lipase-catalyzed lactone ring-opening polymerizations," Macromolecules, vol. 35, no. 14, pp. 5444-5448, 2002.

[29] C. S. Lee, M. T. Ru, M. Haake, J. S. Dordick, J. A. Reimer, and D. S. Clark, "Multinuclear NMR study of enzyme hydration in an organic solvent," Biotechnology and Bioengineering, vol. 57, pp. 686-693, 1998.

[30] N. A. Turner and E. N. Vulfson, "At what temperature can enzymes maintain their catalytic activity?" Enzyme and Microbial Technology, vol. 27, no. 1-2, pp. 108-113, 2000.

[31] A. Klibanov, "Why are enzymes less active in organic solvents than in water?" Trends in Biotechnology, vol. 15, no. 3, pp. 97-101, 1997.

[32] Z. Zhong, S. Schneiderbauer, P. J. Dijkstra, M. Westerhausen, and J. Feijen, "Fast and living ring-opening polymerization of L-lactide initiated with in-situ-generated calcium alkoxides," Journal of Polymers and the Environment, vol. 9, no. 1, pp. 31$38,2001$.

[33] C. Jing-Lei, Y. Ying-Ming, L. Yun-Jie, Z. Li-Ying, Z. Yong, and S. Qi, "Synthesis, characterization of homoleptic guanidino lanthanide complexes and their catalytic activity for the ring-opening polymerization of $\varepsilon$-caprolactone," Journal of Organometallic Chemistry, vol. 689, no. 6, pp. 1019-1024, 2004.

[34] E. Pamuła, P. Dobrzyński, M. Bero, and C. Paluszkiewicz, "Hydrolytic degradation of porous scaffolds for tissue engineering from terpolymer of L-lactide, $\varepsilon$-caprolactone and glycolide," Journal of Molecular Structure, vol. 744-747, pp. 557-562, 2005. 

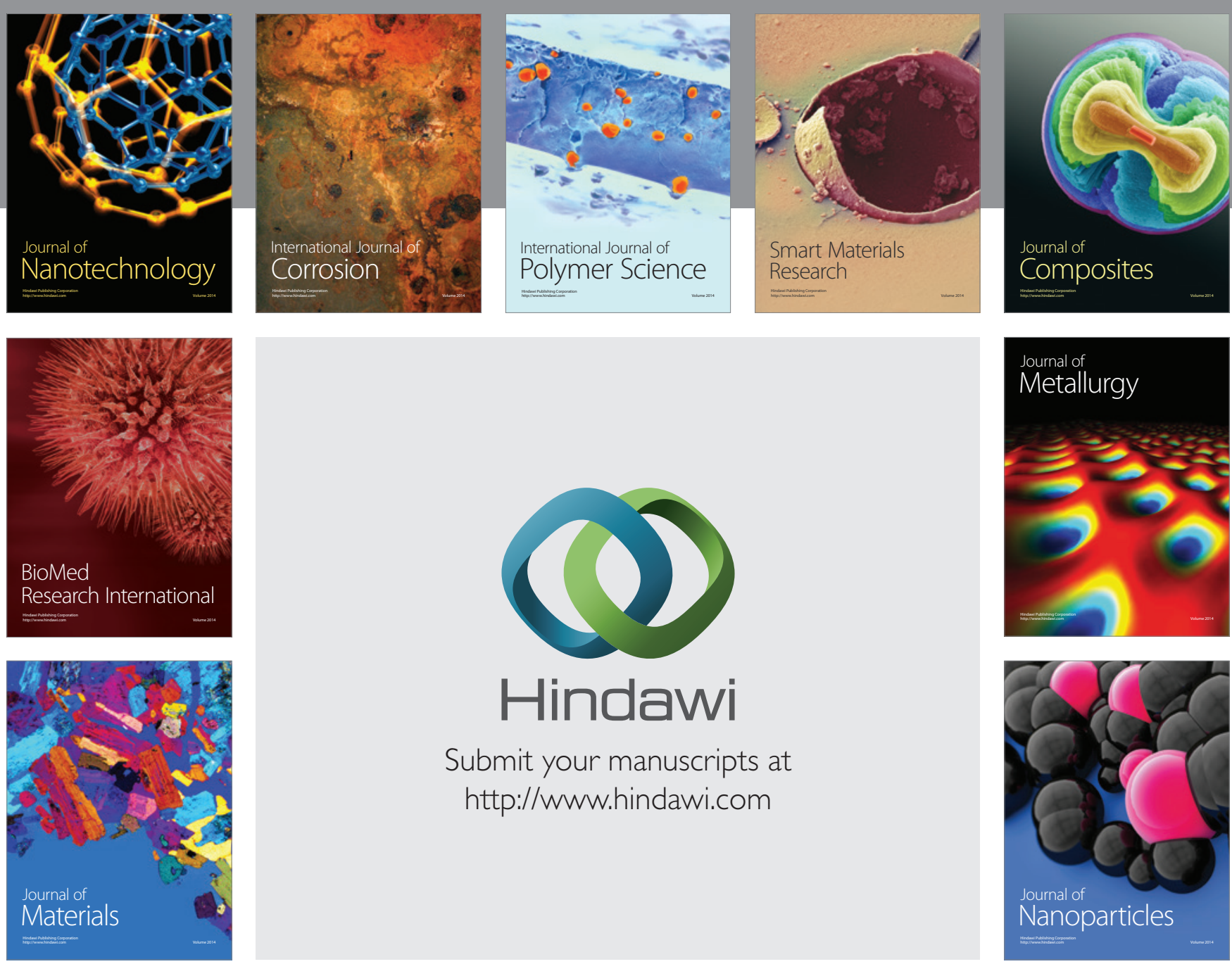

Submit your manuscripts at http://www.hindawi.com
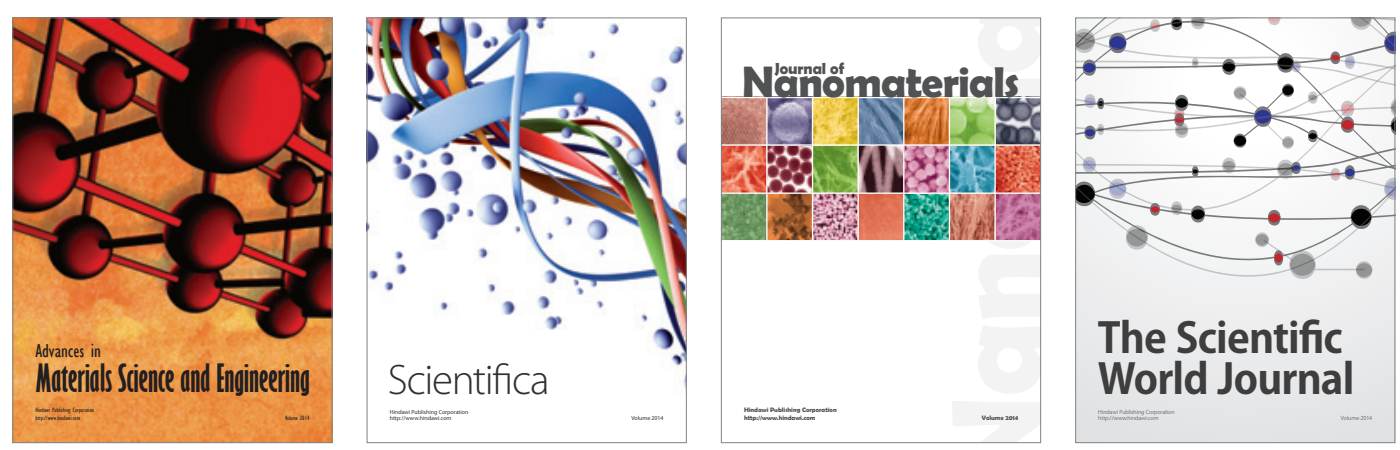

\section{The Scientific World Journal}
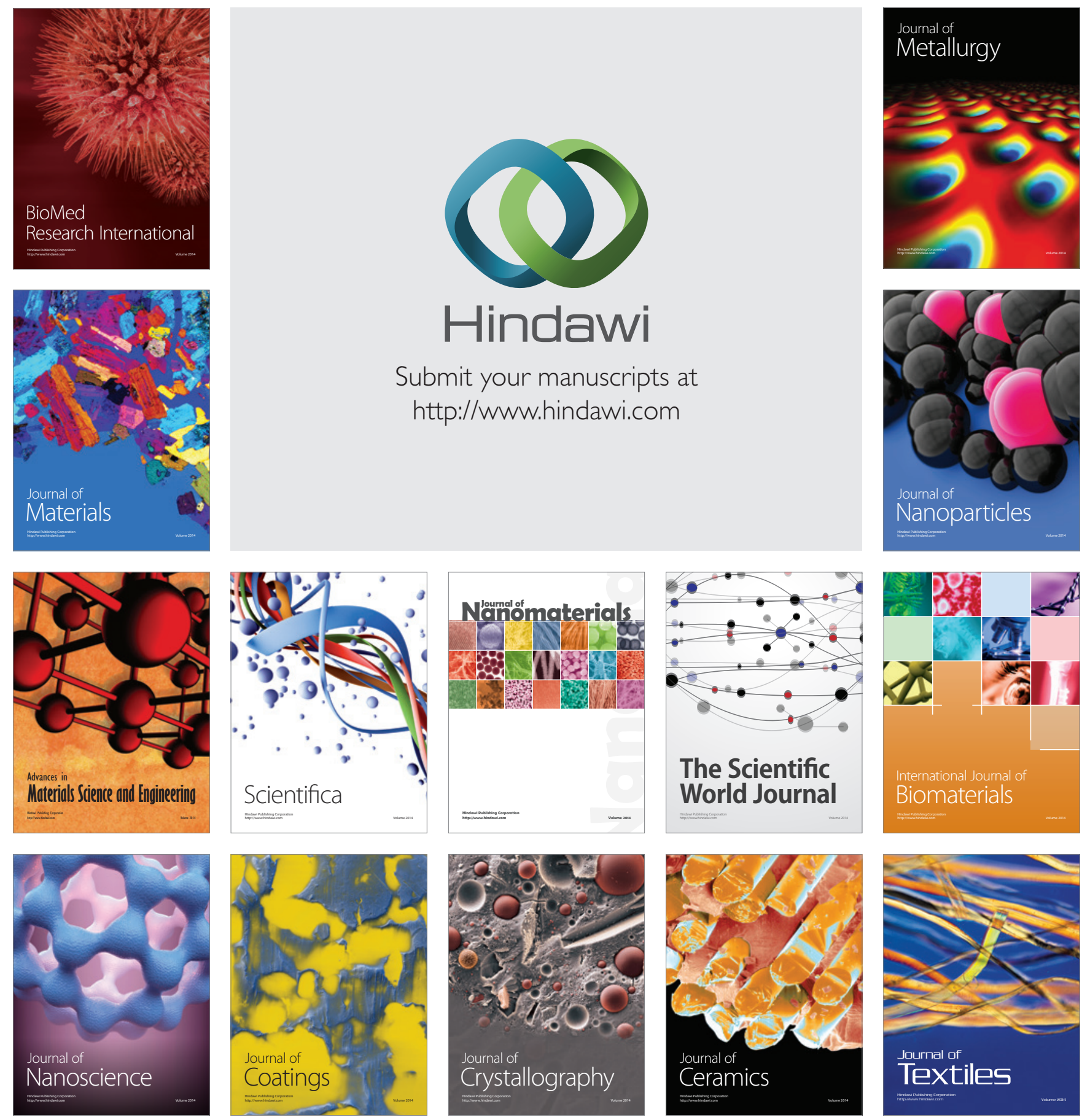